\title{
The Effect of Using Multiple Intelligences Theory Strategy on Developing Some Basketball Skills with Preparatory Schools Pupils
}

\author{
Mohammed Ahmed Abdulmohsen ${ }^{1}$ \\ ${ }^{1}$ Assistant Professor - Faculty of Physical Education for Boys - Helwan University, Egypt
}

\begin{abstract}
The research aims to recognize The Effect of using multiple intelligences theory Strategy on developing some basketball skills with preparatory Schools pupils, the researcher has utilized the experimental method, the sample was (40)pupils, were divided to an experimental group \& a control group, the most important conclusions was utilizing the suggested learning program to improve multiple intelligences with preparatory Schools pupils.
\end{abstract}

Keywords: Strategy- multiple intelligences theory- basketball skills-pupils- preparatory schools

\section{Research problem \&importance:}

$\mathrm{M}$ ultiple intelligences theory Strategy has interpreted this phenomena through study multiple intelligences within individual, it was (linguistic/verbal intelligence or mathematical/logical intelligence or the musical intelligence spatial intelligence ,bodily/kinesthetic intelligence, interpersonal intelligenceemotional intelligence) in high level or about medial, current curriculums has no benefits from this fact in improving academic study level with that people class(Radi Alwakfy 2003 page 51)(Harud Gardner 2005 page 48)

The Researcher found that Sports activities in General and basketball in particular need of practitioners having all kinds of intelligences, so practicing sports activities must work on developing all intelligence of these intelligences to reach a high level of skill level in sports activity type practitioner, prompting researchers to develop the Educational programs using multiple intelligences types in order to develop some skills in practicing sports, and this is confirmed by both (Mohamed Hussein(2003)p.145, Gaber Gaber (2003)p.14.

This is demonstrated by Ahmed Garayhi (2011)study and the results agreed that learning strategies according to multiple intelligences more positive and impressive than the traditional way of learning the skills of various sports.

Through the researcher's notes and follow it to the existing education programs with middle school students, and through his experiences note as general educational programs prepared in advance to suit all students based on their failings or weakness, and researcher interviews to some experts in the field, it turns out that programs Educational offers students most often used traditional methods without taking into account the environment and needs of students as well as being do not pay attention to their talents and preferences and abilities required by these talents and capabilities of a variety of teaching methods to address every pupil to suit his style of learning, which Most learners achieve low levels of improvement in results of achievement tests, and the attendant boredom and develop negative attitudes towards teachers and school in General, many studies have indicated that traditional programs apply without regard to the patterns and strategies of thinking for every pupil. Researcher found that using multiple intelligences strategy includes a range of methods and activities used by the teacher according to the type of pupil than other pupils, And so for other intelligences so the view finder for this study to identify the purpose of using multiple intelligences strategy and identify their impact on the development of some basketball skills among students in preparatory school.

The research aim: the research aims to identify the effect of using multiple intelligences strategy on the development of some basketball skills learners in middle school. 


\section{Terms:}

\section{*Linguistic intelligence}

It is the ability to use words effectively orally (as in a call to exercise or when teaching skills in games class).

\section{*Logic \& Mathematics intelligence:}

It is the ability to use numbers effectively (as when formations composed of digital numbers and the ability to change between different profiles

\section{*Spatial intelligence}

It is the ability to perceive Visual -spatial world accurately Spatial (as when you realize where the learner or a particular formation centre place tools when performing different exercises)

\section{*Physical intelligence}

It is the experience and competence in using learner to his body as a whole to express the desired movement (as is the case when you sport this intelligence skills like balance, dexterity, strength, flexibility, speed and sense of body movement.

Musical intelligence: $*$ is the ability to recognize musical formulas and linked to rhythm movement (as is the case when using music to accompany sports performances).

Social intelligence: $*$ is the ability to understand others ' moods and intentions and motives and feelings and distinguished, this sensitivity to sound good and expressions and gestures and the ability to distinguish between different types and the ability to respond effectively to them in a practical way (as in the teacher's references For learners in physical education class).

Personal intelligence: $*$ is the ability to self-knowledge and ability to act on the basis of such consensual knowledge, this intelligence involves the individual to have an accurate picture (about aspects of his power and its limits) and nihilistic moods of despair, purposes and motivations and inner sense moods and desires and emotional ability and understanding self And appreciation.

\section{Research procedures:}

\section{Research method:}

Use the experimental method with designing an experimental \&control group, pre-post measures because of its appropriated to the research nature

\section{Research community/sample}

This research was conducted on the second grade educated preparatory school with modern prep school boys of the Department of education in Fayoum (160) is educated, and chose the number (60) pupils at random from second grade secondary school learners and chose them at random number ( 40 ) educated by $25 \%$ to apply basic experience and make homogeneity variables (age, height, weight, physical variables, and skill) and divide it into two equal groups by number (20) each learner group, have also been using the number (20) remaining learner to conduct surveys and rationalized The test under discussion.

Data collection tools:

First: the tests for growth rates: age: birth certificate date is referenced to the nearest month. Length: use your Alristameter to the nearest centimeter. Weight: use the medical balance to the nearest $\mathrm{kg}$

II: physical tests: use Finder to measure fitness following tests to adjust the search variables: running is $30 \mathrm{~m}$ from the start of mobile broad jump of fortitude. The shuttle run 40 seconds the enemy $30 \mathrm{~m} / 5$ times( Mohammed Sobhy Hassanein (2011),p.266-283annex (5).

III: basketball skill tests: data were collected by a battery test to measure basic skills in basketball middle school students prepare Mohamed Magdy El badry (2005) (5), is made up of three tests, the first test to measure the speed of scrolling on the echo wall, And the second test to measure the speed of conversation between points, the third test to measure the conversation ended with correction, battery units enjoy honesty and high stability annex (2).

*Pre-measure:

Was conducted for the selected research variables

Smoothing sample research: homogeneity in variables (age, height, weight, physical variables, and skill), a sample of the search (40) educated, pre split them into two groups (control Group, experimental group) ranging from $(-0.20: 0.63)$ and these values are limited between \pm 3 and under The equinoctial signifying smoothing search sample

Exploratory studies: this study was conducted in the period from $1 / 3$ to $15 / 3 / 2017$ for explaining multiple intelligences strategy pilot group learners divide learners into pairs are close in height and weight to performance during program execution. Apply some educational units on pupils. Scientific transactions for physical tests and skill in question.

\section{Scientific transactions:}

1. validity: was found for physical tests and skill in question using the method of differentiation in ratified 1 March $2017 \mathrm{~m}$ on a random sample (20) educated outside of original research and sample of the research community 
to calculate honesty, after arranging their score descending on every test, and determine the minimum spring And upstairs, intermediate comparison using algorithmic test (v) statistical function differences between lower and upper the springs which shows the sincerity of the physical tests and skill under discussion

\section{Stability:}

Be found to physical tests and skill under discussion using a test application and then reapply it as first tests were applied in 1/3/2017 was applied again on the same sample at 15/3/2017 $\mathrm{m}$ interval week between two applications, a random sample (20) from the pupil out of the original research and sample of the research community and it turns out that the correlation coefficients ranging from (0.83:0.92) all statistical function at a level (0.05) indicating the high stability of these tests.

The researcher has carried out pre-post measures for the experimental/control group, to have parity between the two groups in the skill variables under discussion.

Table (4)

Differences between pre-post measures for the experimental/control group in the skill variables with learners in the preparatory school N1=N2=20

\begin{tabular}{|c|c|c|c|c|c|c|c|c|}
\hline \multirow{2}{*}{ Serial } & \multirow{2}{*}{$\begin{array}{c}\text { Statistic variables } \\
\text { Sub-themes }\end{array}$} & \multirow[t]{2}{*}{ Measure unit } & \multicolumn{2}{|c|}{ Control group } & \multicolumn{2}{|c|}{ Experimental group } & \multirow{2}{*}{ Differences between two measures } & \multirow{2}{*}{ T Value } \\
\hline & & & $\mathbf{S}$ & $\mathbf{A}$ & $\mathbf{S}$ & $\mathbf{A}$ & & \\
\hline 1 & Passing speed on the wall & $\mathrm{N} / \mathrm{S}$ & 6,55 & 1,12 & 6,52 & 1,10 & 0,08 & 0,23 \\
\hline 2 & Dripping speed & $\mathrm{S}$ & 7,37 & 1,31 & 7,36 & 1,30 & 0,01 & 0,02 \\
\hline 3 & Dripping with shooting & $\mathrm{S}$ & 10,85 & 1,92 & 10,85 & 1,87 & 0,01 & 0,01 \\
\hline
\end{tabular}

*T Table with $0,05=2,096$

Table (4) illustrates that there is a statistical significant differences between pre-post measures with the experimental/control groups in the skill variables with learners in the preparatory which indicates to a parity between the two groups school

\section{The major study:}

The research aims to recognize the effect of utilizing multiple intelligences strategy in developing some basketball skills with learners in the preparatory school.

\section{Basis of multiple intelligences strategy:}

*Considering that the aim of training achieved multiple intelligences strategy. Taking into *account the thrill and excitement in multiple intelligences strategy components

*Progressivity from easy to hard.

* Using the words of encouragement and immediate measures.

*Multiple intelligences strategy content should be simple and non complicated

*Multiple intelligences strategy content distribution account number of units.

* Taking into account the possibilities and provide the necessary tools.

* Multiple intelligences strategy in line with demographic characteristics, tendencies and trends.
Multiple intelligences strategy content: return to scientific references and previous studies might restrict range of basketball skills that match the search target, as well as the characteristics of the sample, are as follows:-passingdripping-shooting

Steps the program preparation:

* select basketball skills hand by that point.

* Determine the tools used in the strategy of multiple intelligences.

\section{Period of multiple intelligences strategy:}

time for a strategy of multiple intelligences (8) weeks start from 1/3 until 15 March 2017. Specify the number of units weekly lessons per week. Standardize search groups education unit time by 45 minutes are divided into 5minute warm up, 10 minutes of physical preparation, 25 minutes for educational and practical activity (core), (5) conclusion

\section{Post measure:}

The post measure was carried out for (the experimental/control group)I the period of 15/5-16/5/2017 for basketball skills Under discussion with the same order of the pre-measure.

Statistical transactions:

The researcher utilized SPSS , and selected the appropriated transactions 


\section{Results discussion:}

-Differences between pre-post measures with the experimental group utilized (orders style)in the skill tests under discussion

Table (5)

The significant of differences between pre-post measures with the control group (orders style)in Basketball skill tests under discussion $\mathbf{N}=\mathbf{2 0}$

\begin{tabular}{|c|c|c|c|c|c|c|c|}
\hline \multirow{2}{*}{ Tests } & \multirow{2}{*}{$\begin{array}{l}\text { Measure } \\
\text { unit }\end{array}$} & \multicolumn{2}{|c|}{ Pre-measure } & \multicolumn{2}{|c|}{ Post measure } & \multirow{2}{*}{$\begin{array}{l}\text { Differences } \\
\text { between the } \\
\text { two means }\end{array}$} & \multirow{2}{*}{ T Value } \\
\hline & & $\mathrm{S} / \mathbf{1}$ & A1 & $\mathrm{S} / 2$ & A2 & & \\
\hline Passing speed test on the wall & $\mathrm{n} / \mathrm{s}$ & 6,44 & 1,12 & 7,10 & 1,20 &,- 66 & $* 2,36$ \\
\hline Dreppling speed test & $\mathrm{S}$ & 7,36 & 1,31 & 7,04 & 1,17 & 0,32 & 1,07 \\
\hline Dreppling with shooting test & $\mathrm{S}$ & 10,84 & 1,92 & 10,34 & 1,85 & 0,50 & 1,09 \\
\hline
\end{tabular}

T table value with significant $0,05=2,093$

Table (5) illustrates that there is a significant statistical differences between pre-post measures with the control group in passing speed test on a bigger wall for the more number $/ 10 \mathrm{~S}$, while there is no significant statistical differences in dripping speed test, dripping with shooting, that calculated (T) IS LESS than table with $(0,05)$
Differences between pre-post measures with the group with using (the multiple intelligences theory) in the skill test of basketball under discussion

Table (6)

$\mathbf{N}=\mathbf{2 0}$

\begin{tabular}{|c|c|c|c|c|c|c|c|}
\hline \multirow{2}{*}{ Tests } & \multirow{2}{*}{$\begin{array}{c}\text { Measure } \\
\text { unit }\end{array}$} & \multicolumn{2}{|c|}{ Pre-measure } & \multicolumn{2}{|c|}{ Post measure } & \multirow{2}{*}{$\begin{array}{c}\text { Difference } \\
\text { between the two } \\
\text { means }\end{array}$} & \multirow{2}{*}{ T Value } \\
\cline { 3 - 7 } & $\mathrm{S} / \mathbf{1}$ & $\mathbf{A} / \mathbf{1}$ & $\mathbf{S} / \mathbf{2}$ & $\mathbf{A} / \mathbf{2}$ & 1,82 & $-5,58$ & $* 15,5$ \\
\hline $\begin{array}{c}\text { Passing speed on the wall } \\
\text { test }\end{array}$ & $\mathrm{n} / \mathrm{s}$ & 6,52 & 1,10 & 11,10 & 10,05 & 2,25 & $* 7,76$ \\
\hline Dreppling speed test & $\mathrm{S}$ & 7,36 & 1,30 & 5,11 & 1,11 & 3,62 & $* 9,97$ \\
\hline Dreppling with shooting test & $\mathrm{S}$ & 10,84 & 1,87 & 7,15 & & & \\
\hline
\end{tabular}

* T Table value with significant $0,05=2,093$

Table (6) illustrates that there is a significant statistical differences between pre-post measures with using (multiple intelligences theory) in the skill tests of basketball in all skill tests under discussion favor to the post measure

Table (7)

Differences between the two means of pre-post measures for the experimental/control group in the skill tests of basketball $\mathrm{N}=20$

\begin{tabular}{|c|c|c|c|c|c|c|}
\hline \multirow{2}{*}{$\begin{array}{l}\text { Variables } \\
\text { Sub-themes }\end{array}$} & \multicolumn{2}{|c|}{ Control group } & \multicolumn{2}{|c|}{ Experimental group } & \multirow{2}{*}{ Differences between the two measures } & \multirow{2}{*}{ T Value } \\
\hline & $\mathrm{S} / \mathbf{1}$ & A1 & $\mathrm{S} / 2$ & A2 & & \\
\hline Passing speed on the wall test & 7,10 & 1,20 & 11,10 & 1,82 & 4,00 & $* 8,00$ \\
\hline Dreppling speed test & 7,04 & 1,17 & 5,11 & 1,05 & 1,93 & $* 5,36$ \\
\hline Dreppling with shooting test & 10,34 & 1,85 & 7,15 & 1,11 & 3,19 & $* 6,51$ \\
\hline
\end{tabular}

*T Table value with significant $0,05=2,096$

Table (7)illustrates that there is a significant statistical differences between the two post measures with the control/experimental group in the skill tests favor to the experimental group.
Differences of the improvement rates (pre-post measures) with the experimental /control group in the skill tests under discussion

Table (8)

Percentage rate of improvement between the control/experimental group in the skill tests under discussion 


\begin{tabular}{|c|c|c|c|c|c|c|}
\hline \multirow{2}{*}{ Tests } & \multicolumn{3}{|c|}{ Control group } & \multicolumn{3}{c|}{ Experimental group } \\
\cline { 2 - 7 } & Pre & Post & Improvement rate & pre & post & Improvement rate \\
\hline Passing speed on the wall test & 6,44 & 7,10 & $10,5 \%$ & 6,52 & 11,10 & $73,28 \%$ \\
\hline Dreppling speed test & 7,36 & 7,04 & $4,34 \%$ & 7,36 & 5,11 & $* 30,57 \%$ \\
\hline Dreppling with shooting test & 10,84 & 10,34 & $4,61 \%$ & 10,84 & 7,15 & $* 34,04 \%$ \\
\hline
\end{tabular}

Table(8)illustrates that the percentage rates of the improvement rates between pre-post measures for the skill tests for the control group between $(4,34 \%-10,5 \%)$, the experimental group was $(30,57 \%-73,28 \%)$ favor to the post measure for every group.

\section{Results Discussion:}

Table (5) illustrates that there is a significant statistical differences between pre-post measures in the passing on the wall speed for more number/s, hence the calculated $\mathrm{T}$ more than $\mathrm{t}$ Table with significant 0,05 , while there is no significant statistical differences in the two tests of dreppling speed test, dripping with shooting, the results agreed with the study results of Ahmed Ashour(1997) that learning with orders style did not realize the required level in learning basic skills for different sport activities, the researcher attributed it to the style of learning, that it give opportunities to try and repeat to perform skills with an accepted degree from accuracy and commitment with the model.

Table(6)results indicates that there is a significant statistical differences between pre-post measures with the group with using (multiple intelligence theory) in the skill tests of basketball.

The researcher attributes these results to the positive effect of the multiple intelligences learning program with learners of the preparatory school.

These results agreed with results of Kambell study 2009, in which the results of this class clarified that children with law level of study distinguished with motor intelligence, but it is not employed in learning and study.

Those results agreed with (Rebekah, 2004)46, study results, it clarified that there is an improvement in memorizing learning material, increase their involvement and the time spent in the education tasks performance, decrease the un desired behaviors (hyper active)

Those results agreed with(Decker,2007)72, the results clarified that there is a significant statistical between the two styles favor to the students who study according to the multiple intelligences styles.

Those multiple intelligences theory, have gained high scores in studying and increase in their involvement in the learning process .their activation toward learning has increased, they utilized learning styles suitable for the most intelligent of them. The symmetry/harmony have increased with their teachers Table (7) shows that there was a significant statistical differences between the control/experimental group in the skill tests favor to experimental group, while table(8)shows that the percentage rate of the improvement between pre-post measures for the skill tests of the control group was between $(4,34 \%-10,25 \%)$, for the experimental group as in between $(30,57 \%-73,28 \%)$ favor to the post measure for every group.

The researcher attributes the progress in the positive role of the learning program with the learning process in the sport field, when designing education programs as an education tool, save the effort and time of teacher during learning process to help learner to understand sport activities skills, develop the multiple intelligences, the researcher gave interest to attraction side in learning skill and clarify how to perform the skill correctly.

This study agreed with results of (Fortinin,2012)76, which has clarified the improvement of performance level of the study sample in the multiple intelligences, increased their activation to learn.

\section{Conclusions:}

Use the learning proposal to improve multiple intelligences among learners in middle school. Using the proposed tutorial has a positive impact best influence the way explain the teacher in a learning level to improve multiple intelligences among learners in middle school.

\section{Recommendations:}

*learning proposal to improve multiple intelligences among learners in middle school teaching due to increased numbers of learners in the teaching group which helps to exploit time and space saving and upgrading skills for learners.

*Further research and studies on different samples to confirm the effect tutorial to improve multiple intelligences among learners in preparatory school.

* The need for teachers of courses of physical education in preparatory schools to train them on the use of multiple intelligences strategy in teaching sports skills lesson. 


\section{References:}

1- Ahmed Algaraigy(2011): The Effect of Learning Strategy according to Multiple Intelligences on the cognitive Study and Degree of basic skill Performance with Hockey Beginners ,Un published PHD- Port Said University, Faculty of Physical Education for Men \&Girls.

2- Gaber Gaber (2003) : Multiple Intelligences and Understanding, Cairo, Dar Alfekr Alaraby.

3- Rady Alwakfy(2003): Learning Disabilities Introduction:Theory\&Apply,Jordon,Publishes of Kolliat Alamira Thrawat.

4- Mohamed Hussein(2003): Human Brain Educationals ,Jordon, Dar Alfekr for publish Print \&Distribution

5- Mohamed Magdy(2005) Set Two Test Batteries for Evaluate Basic Skills in Basketball \&Handball for the Sport School Students in Alsharkia, Theories, Applications Magazine, Faculty of Physical Education for Girls, Alexandria University. Edition 55
6- Haward Jardrner(2005) Multiple Intelligences in the twentieth century, Alkhozamy Translation, Dar Alfekr Alaraby.Cairo

7- Hoda Hussan (2011) Learning Basic Skills with the Multiple Intelligences on Developing Some Psychological\& Visual Skills with Karate Beginners, unpublished PHD, Faculty of Physical Education for Girls, Zgazig University

8- Wafaa Mahmoud 2012The Impact of Using Some Different Teaching Styles According to Intelligences Types on Learning Some Volleyball Skills, Motor Satisfaction, Unpublished PHD, Helwan University, Faculty of Physical Education for Girls

9- Fotini, B ( 2012 ). What kind of multiple intelligence in formed instruction and assessment can be developed that will help adult learners deal with math anxiety so they reach their stated goals, Boston: national center for learning ( ERIC Documents reproduction service No ED453386) 